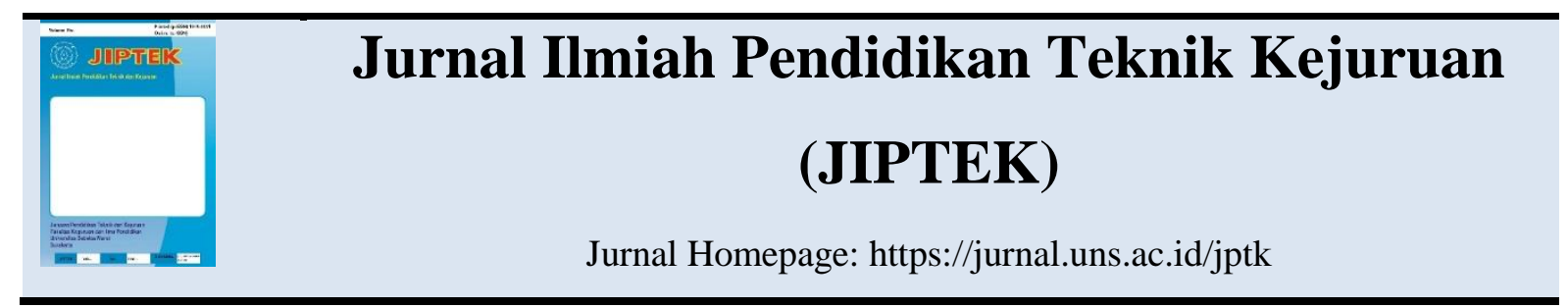

\title{
EVALUASI KINERJA PROGRAM STUDI PENDIDIKAN TEKNIK MESIN FKIP UNS MENGGUNAKAN METODE INTEGRATED PERFORMANCE MEASUREMENT SYSTEMS (IPMS)
}

\author{
Bekti Khonaah, Suharno, Budi Harjanto \\ Program Studi Pendidikan Teknik Mesin, FKIP, Universitas Sebelas Maret Surakarta \\ Jalan Ahmad Yani 200 Surakarta \\ Email: khonaahbekti@gmail.com
}

\begin{abstract}
ABSTRAK
Penelitian ini bertujuan untuk mengevaluasi kinerja dari Program Studi Pendidikan Teknik Mesin. Metode yang digunakan pada penelitian ini adalah (1) Integrated Performance Measurement Systems (IPMS) yang tujuan utamanya adalah merancang sistem pengukuran; (2) Analytical Hierarchy Process (AHP) yang bertujuan untuk melakukan pembobotan indikator; dan (3) Objective Matrix (OMAX) yang bertujuan untuk melakukan pengukuran kinerja. Hasil dari penelitian ini adalah sebagai berikut. Pertama, hasil rancangan pengukuran kinerja terdiri dari 14 indikator yang termasuk dalam 6 kriteria perspektif pengukuran kinerja. Kedua, tingkat kinerja pada tiap Key Performance Indicators (KPI) yang paling tinggi adalah indikator tersedia instrumen baku untuk mengukur kinerja dosen dalam perkuliahan, sedangkan kinerja yang paling rendah adalah indikator 95\% lembar Berita Acara Perkuliahan (BAP). Kinerja Program Studi Pendidikan Teknik Mesin secara keseluruhan memiliki indeks kinerja sebesar 5,055, sehingga kinerja pada Program Studi Pendidikan Teknik Mesin masuk dalam kategori mengalami peningkatan kinerja. Ketiga, kinerja yang perlu ditingkatkan pada Program Studi Pendidikan Teknik Mesin Universitas Sebelas Maret Surakarta terdapat 8 Key Performance Indicators $(K P I)$. Kinerja yang perlu diperbaiki pada Program Studi Pendidikan Teknik Mesin Universitas Sebelas Maret Surakarta adalah 95\% lembar Berita Acara Perkuliahan (BAP) terisi.
\end{abstract}

Kata Kunci: pengukuran kinerja, IPMS, AHP, Pendidikan Teknik Mesin, KPI.

\section{PENDAHULUAN}

Pendidikan merupakan salah satu sarana penting dalam menunjang kemajuan sumber daya manusia dalam era yang semakin maju ini. Masalah yang dihadapi oleh negara kita adalah kurangnya sumber daya manusia yang berkualitas. Penelitian yang diselenggarakan oleh OECD (Organisation for Economic Co-operation Development) pada tahun 2015, menghubungkan antara kualitas pendidikan dengan perkembangan ekonomi. Dari hasil penelitian tersebut, Indonesia mendapatkan peringkat ke 69 dari 76 negara sedunia. Peringkat yang dicapai tersebut menunjukkan bahwa Indonesia merupakan negara dengan kualitas 
pendidikan dan pertumbuhan ekonomi yang rendah.

Evaluasi program menurut Sukardi (2014: 3) adalah evaluasi yang berkaitan dengan suatu program/kegiatan pendidikan, termasuk di antaranya terdapat kurikulum, sumber daya manusia, penyelenggaraan program, serta penelitian dan pengabdian masyarakat dalam suatu lembaga. Tujuan evaluasi adalah untuk memperoleh informasi yang akurat dan objektif tentang suatu program (Eko, 2009: 6).

Evaluasi pada Program Studi Pendidikan Teknik Mesin Universitas Sebelas Maret Surakarta telah dilakukan sebelumnya, namun belum pernah merumuskan Key Performance Indicators (KPI) dengan lebih spesifik dan menghasilkan rancangan sistem pengukuran kinerja secara mandiri. Metode Integrated Performance Measurement Systems (IPMS) bertujuan untuk merancang suatu sistem pengukuran kinerja secara tepat, dalam bentuk integrasi, efisen, dan efektif (Maulidia, Setyanto \& Rahman, 2014: 2). Metode Integrated Performance Measurement Systems (IPMS) merupakan metode pengukuran kinerja dapat dilihat berdasarkan dari kebutuhan tiap stakeholders (Bititci, 2015: 258). Metode ini merupakan metode pengukuran kinerja yang merumuskan identifikasi Key Performance Indicators $(K P I)$ berdasarkan dari kebutuhan stakeholder. Menurut
Syarifuddin (2008: 133) Metode Integrated Performance Measurement Systems (IPMS) memiliki 4 level bisnis (organisasi) yakni Business Corporate (Bisnis Induk), Business Unit (Unit Bisnis), Business Process (Proses Bisnis), dan Activity (Aktivitas Bisnis). Stakeholders ditentukan terlebih dahulu berdasarkan level tersebut, selanjutnya identifikasi kebutuhan/permintaan dari stakeholders yang disebut dengan stakeholders requirement. External monitoring sebagai pembanding antara organisasi dengan pesaing/rekan organisasi. Objectives sebagai tujuan yang harus disusun untuk memenuhi kebutuhan/permintaan stakeholders, sehingga Key Performance Indicators (KPI) dapat ditentukan untuk digunakan sebagai pengukur keberhasilan kinerja dari Program Studi Pendidikan Teknik Mesin. Pembobotan pada masingmasing Key Performance Indicators (KPI) menggunakan pendekatan Analytical Hierarchy Process (AHP). Pernyataan Mulyaningtyas (2009: I-2) yang mengutip dari Saaty bahwa Analytical Hierarchy Process $(A H P)$ adalah prosedur yang berbasis matematis yang sangat baik dan sesuai untuk kondisi evaluasi atribut-atribut kualitatif. Pengukuran kinerja dinilai dengan metode Objective Matrix (OMAX) yang merupakan metode sebagai sarana pengukuran kinerja, alat pemecah masalah kinerja, dan pemantau pertumbuhan kinerja. 
Tujuan dari penelitian ini adalah: (1) Menemukan rancangan pengukuran kinerja Program Studi Pendidikan Teknik Mesin dengan menggunakan metode Integrated Performance Measurement Systems (IPMS), (2) Menemukan tingkat kinerja Program Studi Pendidikan Teknik Mesin diukur dengan menggunakan metode Integrated Performance Measurement Systems (IPMS), dan (3) Menemukan hal-hal apa saja yang perlu ditingkatkan dan diperbaiki pada kinerja Program Studi Pendidikan Teknik Mesin.

\section{METODE PENELITIAN}

Penelitian ini dilaksanakan di Kampus V Pabelan Fakultas Keguruan dan Ilmu Pendidikan Universitas Sebelas Maret Surakarta. Waktu pelaksanaan penelitian dilaksanakan mulai dari bulan Januari 2016 sampai dengan bulan Juli 2016. Subjek pada penelitian ini meliputi: (1) pengelola program studi (2) dosen (3) mahasiswa, dan (4) alumni Program Studi Pendidikan Teknik Mesin Universitas Sebelas Maret Surakarta.

Pengumpulan data pada penelitian ini berdasarkan dari sumber datanya yaitu: (1) data primer meliputi hasil wawancara dan diskusi untuk menentukan perspektif pengukuran kinerja, hasil data kuesioner I, dan hasil data kuesioner II, dan (2) data sekunder yaitu data yang telah ada yang tersusun secara sistematis berupa dokumen- dokumen pada Program Studi Pendidikan Teknik Mesin dan program studi lainnya pada Universitas Sebelas Maret Surakarta.

Teknik analisis data dalam penelitian ini menggunakan metode penelitian evaluasi kuantitatif dengan jenis pendekatan deskriptif. Evaluasi kuantitatif menggunakan instrumen yang menghasilkan data numerikal (angka). Penelitian evaluasi kuantitatif dimaksudkan untuk mengukur kinerja dari suatu program dengan peranan statistika. Pendekatan deskriptif bertujuan untuk membuat deskripsi, gambaran, atau lukisan secara sistematis, faktual, dan akurat mengenai fakta dan sifat serta hubungan antara fenomena yang diselidiki.

\section{HASIL PENELITIAN DAN PEMBAHASAN}

\section{Identifikasi Level Organisasi}

Level organisasi pada penelitian ini diidentifikasi berdasarkan struktur organisasi dalam Universitas Sebelas Maret Surakarta. Adapun hasil identifikasi level organisasi digambarkan sebagai berikut: 


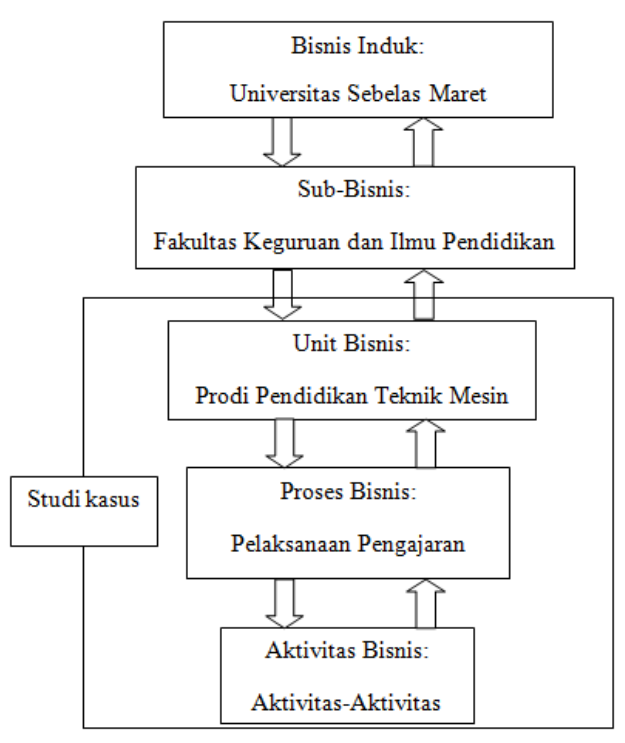

Gambar 1. Level Organisasi PTM

\section{Penentuan Perspektif Pengukuran} Kinerja

Rancangan Perspektif pengukuran kinerja merupakan hasil studi literatur dan wawancara terhadap pengelola Program Studi Pendidikan Teknik Mesin. Rancangan perspektif pengukuran kinerja pada Program Studi Pendidikan Teknik Mesin meliputi: (1) mahasiswa dan lulusan, (2) kurikulum, (3) Sumber Daya Manusia (SDM), (4) proses belajar mengajar (5) administrasi akademik, dan (6) kerjasama dan kemitraan.

\section{Indentifikasi Stakeholders Dan}

\section{Stakeholders's Requirements}

Stakeholders pada penelitian ini meliputi: (1) pengelola program studi (2) dosen (3) mahasiswa, dan (4) alumni Program Studi Pendidikan Teknik Mesin Universitas Sebelas Maret Surakarta. Stakeholders's requirements diperoleh berdasarkan dari hasil data kuesioner II,
Rekapitulasi stakeholders's requirements terhadap Program Studi Pendidikan Teknik Mesin terdapat 11 indikator yang berdasarkan pada perspektif pengukuran kinerja yang telah dirancang sebelumnya.

\section{External Monitoring}

External monitoring dilakukan dengan cara benchmaking antara Program Studi Pendidikan Teknik Mesin Universitas Sebelas Maret Surakarta dengan Program Studi Pendidikan Fisika dan Program Studi Pendidikan Sejarah Universitas Sebelas Maret Surakarta. Indikator kinerja pada Program Studi Pendidikan Teknik Mesin dinyatakan telah menjamin semua aspek yang tertera pada borang akreditas dan memiliki cukup banyak nilai indikator kinerja yang berada di atas Program Studi Pendidikan Fisika dan Program Studi Pendidikan Sejarah.

\section{Penentuan tujuan (objectives)}

Penentuan tujuan (objectives) dirancang untuk memenuhi stakeholders's requirements. Penentuan tujuan (objectives) juga dirancang dengan memperhatikan hasil dari external monitoring. Tujuan (objectives) yang dirancang pada Program Studi Pendidikan Teknik Mesin diperoleh tujuan (objectives) berjumlah 11 kriteria. Seluruh kriteria tersebut merupakan indikator untuk memenuhi stakeholders's requirements. 
6. Penetapan Key Performance Indicators $($ KPI $)$

Key Performance Indicators (KPI) dirancang berdasarkan dari hasil tujuan (objectives). Key Performance Indicators (KPI) merupakan indikator yang akan dipakai untuk melakukan pengukuran kinerja Program Studi Pendidikan Teknik Mesin. Key Performance Indicators (KPI) yang telah dirancang selanjutnya divalidasi menggunakan uji validasi konstruksi (construct validity) dengan menggunakan pendapat dari ahli (experts judgment). Key Performance Indicators (KPI) yang dihasilkan berjumlah 14 indikator dan dijabarkan sebagai berikut:

Tabel 1. Key Performance Indicators $(K P I)$

Key Performance Indicators (KPI)

1. Indeks kepuasan layanan akademik sebesar 3,5.

2. Indeks kepuasan layanan administrasi sebesar 3,5.

3. $95 \%$ lulusan bekerja pada pekerjaan yang sesuai kompetensi.

4. Penambahan minimal 1 orang dosen.

5. Menambah 1 orang yang bertugas melayani administrasi akademik mahasiswa dan lulusan.

6. $95 \%$ lembar Berita Acara Perkuliahan (BAP) terisi.

7. Tersedia instrumen baku untuk mengukur kinerja dosen dalam perkuliahan.

8. Melakukan monitoring pelaksanaan pembelajaran minimal 2 kali dalam 1 semester.

9. Melakukan evaluasi pelaksanaan pembelajaran minimal 2 kali dalam 1 semester.

10. Menambah 2 unit mesin perkakas untuk bengkel mesin.

11. Menambah 1 set alat tune up untuk bengkel otomotif.
12. Mengirimkan tenaga administrasi untuk mengikuti diklat minimal 1 kali dalam 1 tahun.

13. Menambah personil untuk mengelola jaringan sistem informasi untuk area kampus pabelan.

14. Melakukan aktivitas kerja sama dengan instansi luar negeri minimal 1 kali dalam setahun.

7. Spesifikasi Key Performance Indicators (KPI)

Spesifikasi Key Performance Indicators $(K P I)$ merupakan tahap dilakukannya pendeskripsian dengan jelas terhadap tiap-tiap Key Performance Indicators (KPI) yang telah ditetapkan. Adapun contoh spesifikasi Key Performance Indicators (KPI) yang telah dideskripsikan dapat diihat sebagai berikut:

Tabel 2. Spesifikasi (KPI)

\begin{tabular}{|c|c|}
\hline \multicolumn{2}{|r|}{ B.1.1 } \\
\hline Objectives & $\begin{array}{l}\text { Pengembangan kompetensi dan } \\
\text { soft skill mahasiswa }\end{array}$ \\
\hline Nama KPI & $\begin{array}{l}95 \% \text { lulusan bekerja pada } \\
\text { pekerjaan yang } \\
\text { kompetensi }\end{array}$ \\
\hline Target & $95 \%$ \\
\hline $\begin{array}{l}\text { Formula } \\
\text { pengukuran }\end{array}$ & $\begin{array}{l}\text { [Jumlah lulusan yang bekerja } \\
\text { sesuai kompetensi / jumlah } \\
\text { seluruh lulusan] } \times 100 \%\end{array}$ \\
\hline Satuan & Persentase \\
\hline $\begin{array}{l}\text { Frekuensi } \\
\text { pengukuran }\end{array}$ & 1 tahun sekali \\
\hline $\begin{array}{l}\text { Pihak } \\
\text { pengukur }\end{array}$ & Pengelola program studi \\
\hline Sumber data & Alumni \\
\hline
\end{tabular}

\section{Penentuan Pembobotan}

Pembobotan kinerja pada Program Studi Pendidikan Teknik Mesin menggunakan pembobotan global pada seluruh Key 
Performance Indicators (KPI) dengan menggunakan metode Analytical Hierarchy Process (AHP). Bobot global pada Key Performance Indicators (KPI) yang tersusun berdasarkan urutan peringkat kepentingan yang dapat dilihat sebagai berikut:

Tabel 3. Pembobotan global

\begin{tabular}{cc}
\hline Key Performance Indicators $(K P I)$ & $\begin{array}{c}\text { Bobot } \\
\text { Global }\end{array}$ \\
\hline $\begin{array}{c}\text { 1. } 95 \% \text { lembar Berita Acara Perkuliahan } \\
\text { (BAP) terisi. }\end{array}$ & 0,133 \\
\end{tabular}

2. Menambah 2 unit mesin perkakas 0,128 untuk bengkel mesin.

3. $95 \%$ lulusan bekerja pada pekerjaan $\quad 0,112$ yang sesuai kompetensi.

4. Menambah 1 set alat tune up untuk 0,101 bengkel otomotif.

5. Tersedia instrumen baku untuk 0,096 mengukur kinerja dosen dalam perkuliahan.

6. Melakukan aktivitas kerja sama dengan instansi luar negeri minimal 1 kali dalam setahun.

7. Indeks kepuasan layanan akademik 0,082 sebesar 3,5.

8. Melakukan evaluasi pelaksanaan pembelajaran minimal 2 kali dalam 1 semester.

9. Melakukan monitoring pelaksanaan pembelajaran minimal 2 kali dalam 1 semester.

10. Penambahan minimal 1 orang dosen.

0,042

11. Mengirimkan tenaga administrasi untuk mengikuti diklat minimal 1 kali dalam 1 tahun.

12. Menambah personil untuk mengelola jaringan sistem informasi untuk area kampus pabelan.

13. Indeks kepuasan layanan administrasi $\quad 0,019$ sebesar 3,5.

14. Menambah 1 orang yang bertugas melayani administrasi akademik mahasiswa dan lulusan.
Berdasarkan hasil pembobotan pada Key

Performance Indicators (KPI) secara keseluruhan dapat dilihat bahwa indikator kinerja dengan peringkat kepentingan teratas adalah indikator lembar Berita Acara Perkuliahan (BAP) terisi $(0,133)$ dan indikator dengan peringkat terendah adalah indikator menambah 1 orang yang bertugas melayani administrasi akademik mahasiswa dan lulusan $(0,012)$.

\section{Penyusunan Model Pengukuran Kinerja}

Penyusunan model kinerja dilakukan dengan menggunakan metode Objective Matrix (OMAX). Hasil penyusunan model kinerja diperoleh dari perhitungan hasil kinerja, penetapan sasaran skor, penentuan skor pada masing-masing Key Performance Indicators (KPI), perhitungan nilai kinerja, dan perhitungan indeks kinerja. Secara umum perhitungan pengukuran nilai kinerja dapat dilihat pada gambar berikut:

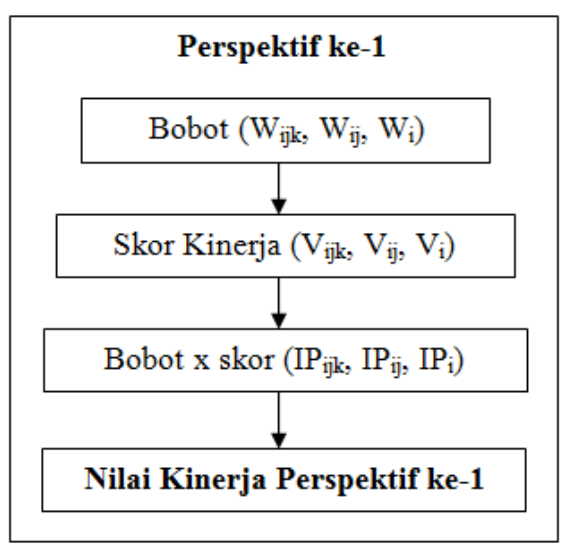

Gambar 2. Perspektif Pengukuran Kinerja 
Adapun hasil dari penyusunan model pengukuran kinerja dapat dilihat pada gambar berikut:

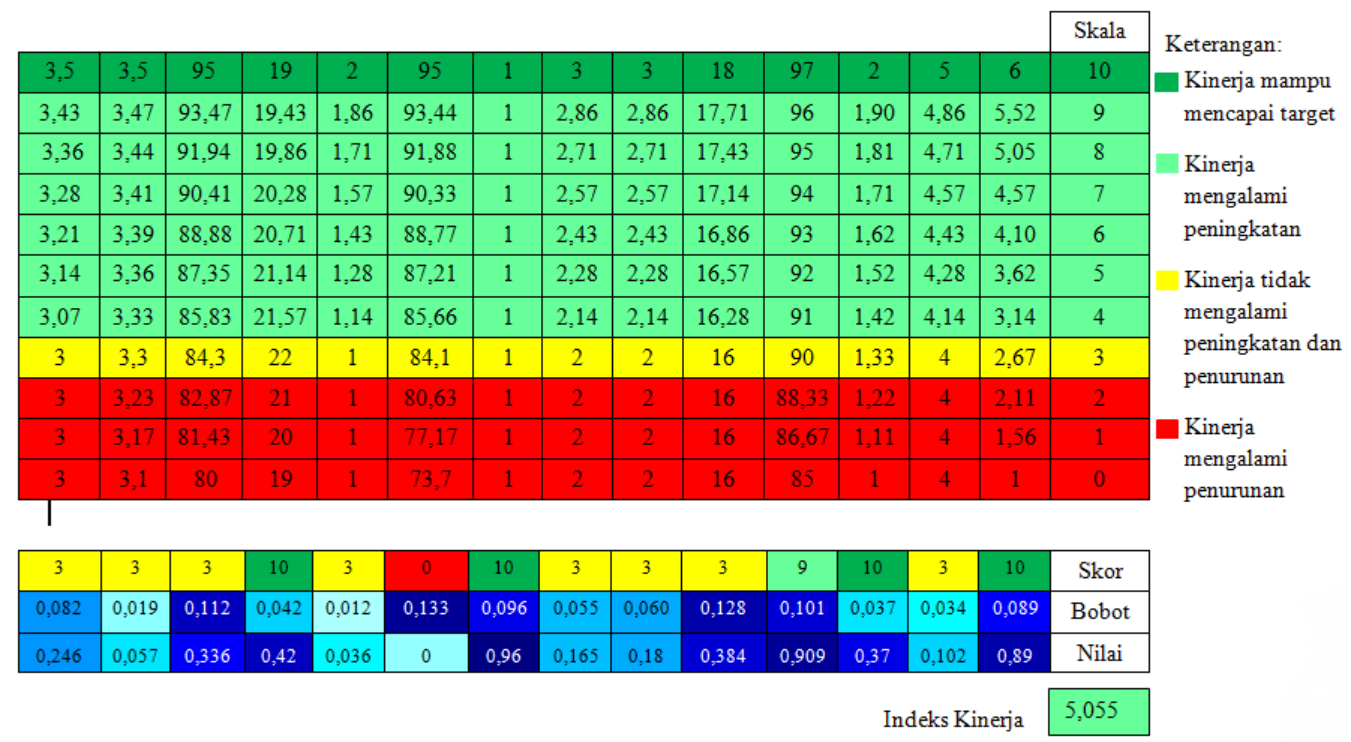

Gambar 3. Model Pengukuran Kinerja pada Program Studi Pendidikan Teknik Mesin Universitas Sebelas Maret Surakarta

Berdasarkan penyusunan model pengukuran kinerja pada Gambar 3. indikator C.4.1 yaitu tersedia instrumen baku untuk mengukur kinerja dosen dalam perkuliahan $(0,96)$ dan indikator D.2.2 yaitu menambah 1 set alat tune up untuk bengkel otomotif $(0,909)$ merupakan indikator yang memperoleh nilai kinerja yang paling besar. Indikator C.3.1 yaitu indikator 95\% lembar Berita Acara Perkuliahan (BAP) (0) dan indikator C.2.1 yaitu indikator menambah 1 orang yang bertugas melayani administrasi akademik mahasiswa dan lulusan $(0,036)$ merupakan indikator yang memperoleh nilai kinerja yang paling kecil.

Pengukuran kinerja dilihat berdasarkan dari skor kinerja, maka indikator penambahan minimal 1 orang dosen (C.1.1), indikator tersedia instrumen baku untuk mengukur kinerja dosen dalam perkuliahan (C.4.1), dan

$$
\text { indikator mengirim tenaga }
$$
administrasi untuk mengikuti diklat minimal 1 kali dalam 1 tahun (E.1.1), serta indikator melakukan aktivitas kerjasama dengan instansi luar negeri minimal 1 kali dalam setahun (F.1.1), memiliki skor masingmasing 10 dan merupakan indikator dengan skor kinerja tertinggi. Sedangkan hasil evaluasi kinerja berdasarkan skor kinerja dapat dilihat pada tabel berikut ini: 
Tabel 4. Hasil Evaluasi Kinerja Berdasarkan Skor Kinerja

\begin{tabular}{|c|c|}
\hline Kategori & Key Performance Indicators $(K P I)$ \\
\hline $\begin{array}{c}\text { Mengalami penurunan } \\
\text { kinerja }\end{array}$ & 1. $95 \%$ lembar Berita Acara Perkuliahan (BAP) terisi \\
\hline $\begin{array}{l}\text { Tidak mengalami } \\
\text { peningkatan ataupun } \\
\text { penurunan kinerja }\end{array}$ & $\begin{array}{l}\text { 1. Indeks kepuasan layanan akademik sebesar 3,5 } \\
\text { 2. Indeks kepuasan layanan administrasi sebesar } 3,5 \\
\text { 3. 95 \% lulusan bekerja pada pekerjaan yang sesuai kompetensi } \\
\text { 4. Menambah } 1 \text { orang yang bertugas melayani administrasi } \\
\text { akademik mahasiswa dan lulusan } \\
\text { 5. Melakukan monitoring pelaksanaan pembelajaran minimal } 2 \text { kali } \\
\text { dalam } 1 \text { semester } \\
\text { 6. Melakukan evaluasi pelaksanaan pembelajaran minimal } 2 \text { kali } \\
\text { dalam } 1 \text { semester } \\
\text { 7. Menambah } 2 \text { unit mesin perkakas untuk bengkel mesin } \\
\text { 8. Menambah personil untuk mengelola jaringan sistem informasi } \\
\text { untuk area kampus pabelan }\end{array}$ \\
\hline $\begin{array}{c}\text { Mengalami } \\
\text { peningkatan kinerja }\end{array}$ & 1. Menambah 1 set alat tune up untuk bengkel otomotif \\
\hline $\begin{array}{l}\text { Mampu mencapai } \\
\text { target kinerja yang } \\
\text { telah ditetapkan }\end{array}$ & $\begin{array}{l}\text { 1. Penambahan minimal } 1 \text { orang dosen } \\
\text { 2. Tersedia instrumen baku untuk mengukur kinerja dosen dalam } \\
\text { perkuliahan } \\
\text { 3. Mengirimkan tenaga administrasi untuk mengikuti diklat } \\
\text { minimal } 1 \text { kali dalam } 1 \text { tahun } \\
\text { 4. Melakukan aktivitas kerja sama dengan instansi luar negeri } \\
\text { minimal } 1 \text { kali dalam setahun }\end{array}$ \\
\hline
\end{tabular}

Berdasarkan pada Tabel 4. evaluasi kinerja pada tiap-tiap Key Performance Indicators $(K P I)$ dikelompokkan menjadi 4 kategori meliputi: (1) kategori mengalami penurunan kinerja 1 indikator, (2) kategori tidak mengalami peningkatan ataupun penurunan kinerja 8 indikator, (3) kategori mengalami peningkatan kinerja 1 indikator, dan (4) kategori mampu mencapai target kinerja 4 indikator.

Indeks kinerja pada Program Studi Pendidikan Teknik Mesin Universitas Sebelas Maret Surakarta adalah 5,055. Indeks kinerja tersebut berada pada skala 310, sehingga dapat disimpulkan bahwa kinerja pada Program Studi Pendidikan
Teknik Mesin Universitas Sebelas Maret Surakarta mengalami peningkatan kinerja dalam satu tahun terakhir ini.

\section{SIMPULAN DAN SARAN}

\section{Simpulan}

Berdasarkan hasil analisa dan pembahasan yang telah dilakukan maka diperoleh simpulan sebagai berikut:

1. Rancangan pengukuran kinerja dilakukan dengan menggunakan metode Integrated Performance Measurement Systems (IPMS). Hasil rancangan pengukuran kinerja tersebut adalah sebagai berikut: 
a. Key Performance Indicators (KPI) pada perspektif pengukuran kinerja mahasiswa terdapat 2 indikator.

b. Key Performance Indicators (KPI) pada perspektif pengukuran kinerja kurikulum terdapat 1 indikator.

c. Key Performance Indicators (KPI) pada perspektif pengukuran kinerja sumber daya manusia terdapat 4 indikator.

d. Key Performance Indicators (KPI) pada perspektif pengukuran kinerja proses belajar mengajar terdapat 4 indikator.

e. Key Performance Indicators (KPI) pada perspektif pengukuran kinerja administrasi akademik terdapat 2 indikator.

f. Key Performance Indicators (KPI) pada perspektif pengukuran kinerja kerjasama dan kemitraan terdapat 1 indikator.

2. Kinerja pada Program Studi Pendidikan Teknik Mesin Universitas Sebelas Maret Surakarta yang didapat dari pengukuran kinerja dengan menggunakan model pengukuran pada metode Objective Matrix $(O M A X)$ adalah sebagai berikut:

a. Kinerja paling tinggi berdasarkan nilai kinerja adalah indikator tersedia instrumen baku untuk mengukur kinerja dosen dalam perkuliahan $(0,96)$, lalu disusul dengan indikator menambah 1 set alat tune up untuk bengkel otomotif $(0,909)$, dan indikator melakukan aktivitas kerjasama dengan instansi luar negeri minimal 1 kali setahun $(0,89)$. Kinerja paling rendah adalah indikator indeks kepuasan layanan administrasi sebesar $3,5(0,057)$, indikator menambah 1 orang yang bertugas melayani administrasi akademik mahasiswa dan lulusan (0,036), dan yang paling rendah adalah indikator $95 \%$ lembar Berita Acara Perkuliahan (BAP) terisi (0).

b. Kinerja tertinggi jika dilihat dari skornya adalah indikator penambahan minimal 1 orang dosen, indikator tersedia instrumen baku untuk mengukur kinerja dosen dalam perkuliahan, indikator mengirim tenaga administrasi untuk mengikuti diklat minimal 1 kali dalam 1 tahun, dan indikator melakukan aktivitas kerjasama dengan instansi luar negeri minimal 1 kali dalam setahun, keempat indikator tersebut memperoleh skor 10. Kinerja terendah dengan skor 0 adalah indikator $95 \%$ lembar Berita Acara Perkuliahan (BAP) terisi.

c. Kinerja pada Program Studi Pendidikan Teknik Mesin Universitas Sebelas Maret Surakarta secara keseluruhan memiliki indeks kinerja sebesar 5,055, sehingga kinerja pada 
satu tahun terakhir dikategorikan mengalami peningkatan kinerja.

3. Kinerja yang perlu ditingkatkan pada Program Studi Pendidikan Teknik Mesin Universitas Sebelas Maret Surakarta adalah indeks kepuasan layanan akademik sebesar 3,5, indeks kepuasan layanan administrasi sebesar 3,5, $95 \%$ lulusan bekerja pada pekerjaan yang sesuai kompetensi, menambah 1 orang yang bertugas melayani administrasi akademik mahasiswa dan lulusan, melakukan monitoring pelaksanaan pembelajaran minimal 2 kali dalam 1 semester, melakukan evaluasi pelaksanaan pembelajaran minimal 2 kali dalam 1 semester, menambah 2 unit mesin perkakas untuk bengkel mesin, dan menambah personil untuk mengelola jaringan sistem informasi untuk area kampus pabelan. Kedelapan indikator tersebut khususnya indikator menambah mesin pekakas untuk bengkel mesin harus diperhatikan dan lebih ditingkatkan, karena indikator tersebut dapat menunjang kegiatan belajar mengajar dan peningkatan kualitas serta pemahaman kompetensi mahasiswa. Kinerja yang perlu diperbaiki pada Program Studi Pendidikan Teknik Mesin Universitas Sebelas Maret Surakarta adalah 95\% lembar Berita Acara Perkuliahan (BAP) terisi. Indikator 95\% lembar Berita Acara Perkuliahan (BAP) terisi berada dalam kategori darurat dan harus secepatnya dilakukan perbaikan. Untuk kinerja yang telah berada pada kategori mampu mencapai target dan mengalami peningkatan perlu dipertahankan agar tetap dalam keadaan baik dan meningkat.

\section{Saran}

1. Program Studi Pendidikan Teknik Mesin UNS

a. Program Studi Pendidikan Teknik Mesin diharapkan dapat mempertahankan kinerja jumlah dosen, instrumen pengukuran kinerja dosen dalam perkuliahan, diklat untuk tenaga administrasi, aktivitas kerjasama dengan instansi luar negeri, dan peningkatan alat tune up agar tetap meningkat.

b. Program Studi Pendidikan Teknik Mesin diharapkan dapat meningkatkan indeks kepuasan layanan akademik sebesar 3,5, indeks kepuasan layanan administrasi sebesar 3,5, $95 \%$ lulusan bekerja pada pekerjaan yang sesuai kompetensi, menambah 1 orang yang bertugas melayani administrasi akademik mahasiswa dan lulusan, melakukan monitoring pelaksanaan pembelajaran minimal 2 kali dalam 1 semester, melakukan evaluasi pelaksanaan pembelajaran minimal 2 kali dalam 1 semester, menambah 2 unit mesin 
perkakas untuk bengkel mesin, dan menambah personil untuk mengelola jaringan sistem informasi untuk area kampus pabelan.

c. Program Studi Pendidikan Teknik Mesin diharapkan dapat memperbaiki tugas dosen dalam mengisi lembar Berita Acara Perkuliahan (BAP) karena indikator tersebut berada dalam kategori darurat dan harus segera dilakukan perbaikan.

d. Program Studi Pendidikan Teknik Mesin perlu memiliki sistem pengukuran kinerja yang dapat merancang sistem pengukuran kinerja secara mandiri dan mengukur indikator kinerjanya secara akurat.

2. Lembaga Pendidikan

Diharapkan bagi lembaga pendidikan lainnya untuk dapat menggunakan metode Integrated Performance Measurement Systems (IPMS) untuk merancang sistem pengukuran kinerja secara mandiri, mengevaluasi kinerja, dan dapat memperbaiki kinerjanya berdasarkan dari hasil pengevaluasian yang telah dilakukan.

\section{DAFTAR PUSTAKA}

Bititci, U. S. (2015). Managing Business Performance. United Kingdom: Wiley.

Maulidia, F. R., Setyanto, N. W., \& Rahman, A. (2014). Perancangan Sistem Pengukuran Kinerja dengan Metode Integrated Performance Measurement Systems (IPMS) (Studi Kasus: KPRI universitas Brawijaya). Jurnal Performa Vol. 2 No. 1.

Mulyatiningsih, E. (2013). Metode Penelitian Terapan Bidang Pendidikan. Yogyakarta: Alfabeta.

Sukardi. (2014). Evaluasi Program Pendidikan dan Kepelatihan. Yogyakarta: PT Bumi Aksara.

Syairuddin, B., \& Suwignjo, P. (2007). Perancangan dan Implementasi Sistem Pengukuran Kinerja dengan Metode Integrated Performance Measurement Systems (Studi Kasus: Jurusan Teknik Mesin Universitas Mataram). Jurnal Teknik Industri Vol. 9 No. 2.

Widoyoko, E. P. (2014). Evaluasi Program Pembelajaran. Yogyakarta: Pustaka Pelajar. 